\title{
Estudo de variáveis especificadoras da tomada de decisão, na organização do ataque, em voleibol feminino
}

\author{
José Afonso \\ Isabel Mesquita \\ Rui Marcelino
}

\author{
Faculdade de Desporto \\ Universidade do Porto \\ Portugal
}

https://doi.org/10.5628/rpcd.08.01.137

\section{RESUMO}

As variáveis contextuais, especificadoras dos cenários de jogo, interferem na tomada de decisão das atletas aquando da realização do ataque e do bloco. Pretendeu-se efectuar a análise exploratória das variáveis: a) disponibilidade da central para o ataque rápido; b) movimentações do bloco antes do passe; c) oposição do bloco, assim como, estudar as relações existentes entre elas, no jogo de Voleibol feminino. Após validação do instrumento de observação (construção e conteúdo) foram analisadas 472 sequências de ataque e de bloco resultantes de 18 sets, duma Poule de Apuramento para o Campeonato da Europa de 2005. A fiabilidade da observação foi comprovada através do índice de fiabilidade Kappa e os procedimentos estatísticos utilizados foram as frequências, percentagens e teste do Qui-Quadrado. Os principais resultados indicam que: i) em mais de metade das sequências observadas não há uma real disponibilidade da central para atacar; ii) a situação de espera das blocadoras perante o passe de ataque é a mais comum; iii) o bloco duplo é o mais utilizado, sendo seguido pelo bloco individual; iv) todas as relações estudadas (disponibilidade da central para o ataque rápido e movimentações do bloco antes do passe; disponibilidade da central para o ataque rápido e oposição do bloco; movimentações do bloco antes do passe e oposição do bloco) apresentam um grau de associação moderado. Com este estudo demonstrou-se que a disponibilidade da central para o ataque rápido influiu decisivamente nas acções do bloco adversário, antes e após o passe de ataque.

Palavras-chave: análise do jogo, tomada de decisão, bloco, ataque rápido, voleibol feminino

\section{ABSTRACT \\ Study on contextual specifier variables of decision making in attack organization in female volleyball}

The contextual specifier variables of the match scenarios, interfere with the athletes' tactical decision making, when attacking and blocking. This paper intended to explore the following variables: a) availability of the middle attacker for the quick attack; $b$ ) block movements previous to the set; c) block opposition, and also, study the relationships between the three variables, within the women's Volleyball game. After validating the observation instrument (construct and content validation), we analyzed 472 sequences of attack and block, from 18 sets relative to a Classification Pool relating to the 2005 European Championships. The observation reliability was asserted through Kappa's Reliability Index. The statistical procedures used were frequencies, percentages and Chi-Square. The main results show that: $i)$ in more than half of the sequences, the middle attacker isn't available for the quick attack; ii) before the set, the block tends to wait, instead of moving; iii) the double block is the most common, followed by individual block; iv) every relationship studied revealed a moderate degree of association. With this study it has been demonstrated that the availability of the middle attacker for the quick attack influences the actions of the opposite block in a decisive way, before and after the set.

Key-words: match analysis, decision making, block, quick attack, female volleyball 


\section{INTRODUÇÃo}

A investigação realizada no âmbito dos jogos desportivos (JD), através da análise de jogo, tem vindo a produzir conhecimento válido acerca das regularidades do jogo. Todavia, a relação entre variáveis especificadoras que antecedem ou proporcionam as acções não tem sido alvo de análise. O seu estudo permitirá um conhecimento mais específico e ecológico, evidenciando o papel da percepção calibrada da informação disponível, na tomada de decisão. Aliás, a investigação mais recente tem vindo a enfatizar a importância dos factores perceptivo-decisionais, considerando-se, justamente, que a percepção calibrada da informação disponível no envolvimento é crucial para a tomada de decisão apropriada $(3 ; 44)$.

No Voleibol, constata-se que o ataque é a acção mais correlacionada com a vitória $(8 ; 14 ; 26 ; 30)$. Na análise do ataque, a trajectória imprimida à bola pela acção de distribuição é preditiva da eficácia desta acção, sendo conhecido que o ataque de tempo rápido tem uma elevada eficácia e configura-se como um meio poderoso na manipulação do bloco adversário, em proveito da equipa atacante $(2,9,10,12 ; 16,27)$.

Diversos autores $(7,10,30,31,33)$ alertam para a necessidade de as blocadoras analisarem os posicionamentos e movimentações dos atacantes adversários. Todavia, a análise de variáveis contextuais, especificadoras dos cenários de jogo, e que podem interferir na tomada de decisão táctica, não tem sido considerada na investigação. Nomeadamente, a disponibilidade da atacante central é decisiva para a construção do ataque rápido, para a realização de ataques de combinação e, ainda, para ludibriar as blocadoras adversárias. Se a atacante central não estiver disponível, as opções de distribuição e de dissimulação da distribuidora reduzem-se drasticamente, permitindo maior antecipação por parte do bloco $(10,17,38)$. Aliás, o Voleibol moderno tende a produzir um jogo de ataque muito rápido, não apenas no centro da rede, mas igualmente pelas alas $(9$, 10, 12, 16, 27).

Consequentemente, o bloco tem vindo a adaptar-se, sendo as movimentações do bloco antes do passe de ataque decisivas para a obtenção de eficácia, através da neutralização da acção de ataque e/ou pela minimização dos seus efeitos. Para tal, a marcação defensiva de uma equipa deve ser activa, não esperando passivamente a actuação do adversário (5). Este princípio, quando aplicado ao Voleibol, pressupõe que as blocadoras ajustem o seu posicionamento, ainda antes da execução do passe de ataque.

A literatura da especialidade $(13,30,33,39)$ considera predominantemente dois tipos de estratégias da acção de bloco, o read-block (ler e reagir) e o commit block (compromisso), que deverão ser empregues em função do adversário e da situação ${ }^{(6)}$. A estratégia de ler e reagir exige a análise da acção ofensiva, o que pressupõe que o blocador espere pela realização do passe de ataque para agir $(30,42)$, revelando-se eficaz na maioria das situações (13). Constitui a melhor opção para enfrentar equipas que canalizam o seu jogo pelas alas e que possuem um primeiro tempo lento (30).

O bloco de compromisso utiliza-se quando a estratégia de ler e reagir não é suficiente, face a ataques rápidos e imprevisíveis ${ }^{42}$, constituindo uma estratégia de antecipação. Com este tipo de estratégia, o blocador salta antes do atacante de primeiro tempo, ou simultaneamente com este, visando neutralizar o ataque rápido $(13,42)$. Esta opção dificulta o apoio nas pontas, sobretudo com passes rápidos, devendo ser utilizado apenas contra equipas cujo ataque pelo meio é rápido e eficaz (30).

O facto de, no Voleibol actual, os blocadores tenderem a possuir uma maior estatura, confere-lhes mais tempo para agir (10), o que pode reduzir, de certo modo, a necessidade de realizar a estratégia de compromisso. Afonso, Mesquita e Palao (1) estudaram, em Voleibol masculino de alto nível, a opção por realizar este tipo de estratégia de bloco, tendo concluído que promovia menos situações de bloco duplo e triplo, além de não se ter observado qualquer diminuição da eficácia do ataque, nem sequer aumento da eficácia do bloco, pelo que a sua utilização deve ser criteriosa.

Relativamente à oposição do bloco, em função do número de blocadores que participam nesta acção, poderá ser de $0,1,2$ ou 3 blocadores, sendo que o bloco duplo se assume como o mais frequente, independentemente das condições iniciais $(1,9,22$, $32,39)$. O bloco individual constitui-se como a segunda ocorrência mais frequente, seguido das situações menos usuais de bloco triplo e de zero blocadores (36). 
A identificação do número de blocadoras que efectivam a oposição do ataque, sem deixar de ser importante, revela-se insuficiente, porquanto não especifica os constrangimentos situacionais explicativos da sua efectivação. Importa identificar, sobretudo, as particularidades situacionais que ditam a realização de determinado tipo de oposição, nomeadamente pela exploração da interferência, ou não, do adversário na decisão de blocar. Por outro lado, importa atender à coesão do bloco. De forma genérica, o bloco coeso é aquele que não dá espaço para que o atacante explore as suas falhas, estando compacto, sendo o bloco aberto caracterizado por existir espaço entre os dois blocadores. O bloco quebrado é aquele no qual a blocadora, chegando atrasada, compensa com a acção dos braços, colocando-os em diagonal (35).

Assim, constituem-se como objectivos deste estudo fazer a análise exploratória das variáveis: a) disponibilidade da central para o ataque rápido, b) movimentações do bloco antes do passe; c) oposição do bloco; e, ainda, proceder a uma análise associativa destas variáveis, no jogo de Voleibol feminino do escalão Sénior. Pretende criar-se um instrumento de observação válido para estas variáveis, aplicável a equipas de nível médio Europeu, merecendo a sua adaptação quando aplicado a equipas de rendimento distinto.

\section{METODOLOGIA}

\section{Amostra}

Para o presente estudo, recorremos a uma amostra de 6 jogos duma Poule de Apuramento para o Campeonato da Europa de 2005, em Seniores Femininos. A escolha dos jogos observados teve como critério que todas as equipas fossem analisadas pelo menos contra dois adversários distintos, no sentido das regularidades encontradas não resultarem das idiossincrasias do adversário, mas sim da lógica inerente ao jogo.

Foram analisados 18 sets, totalizando 472 sequências de ataque e de bloco. A análise de cada sequência começou com a realização do primeiro toque (recepção ou defesa) e terminou após o terceiro toque. Por se considerar que a análise das movimentações do bloco só faz sentido quando o ataque tem características ofensivas, as situações de freeball $^{\mathbf{1}}$ não foram alvo de análise. As situações de downball ${ }^{2}$ foram analisadas, porquanto se exige que o adversá- rio assuma posições defensivas baixas, além de inibir a penetração precoce da distribuidora. ${ }^{3}$

A análise não diferenciou as acções após recepção e após defesa, uma vez que um dos objectivos principais do estudo consistiu na catalogação das possibilidades de ocorrência para cada variável. Interessou, assim, perceber que tipo de situações emergem no jogo, mais do que o momento em que ocorrem.

\section{Instrumento}

Em virtude de não se encontrar descrito na literatura nenhum instrumento que correspondesse às particularidades do problema em estudo, procedeu-se a um processo de validação do instrumento. Para a validação da construção recorreu-se à revisão da literatura da especialidade e à análise dos instrumentos existentes que comportavam as variáveis disponibilidade da central para o ataque rápido, movimentações do bloco antes do passe de ataque e oposição do bloco $(9,10,16,27,30,33)$.

Com o objectivo de proceder à validação do conteúdo, procurou-se saber se as categorias identificadas respondem ao problema colocado. Para a categorização das variáveis, utilizámos o Formato de Campo (25), de forma a elaborarmos um catálogo de ocorrências que mapeasse fidedignamente o jogo. A validação de conteúdo decorreu em duas fases. Numa primeira fase, uma vez que não possuíamos contacto com este desenho metodológico e instrumental, optámos por analisar um só jogo da amostra considerada (65 sequências), com o propósito de iniciar a elaboração do catálogo de ocorrências (quadro 1) e de adquirir sensibilidade face ao problema em estudo. Aplicou-se o critério de análise exclusiva das jogadas que culminassem num passe de ataque. Numa segunda fase, recorreu-se a uma Observação alargada pelo recurso aos restantes cinco jogos da amostra (407 sequências). Mantivemos o Formato de Campo de forma a incluir outras variáveis que pudessem surgir. A observação alargada possibilitou a inclusão de novas ocorrências. Na variável oposição do bloco, surgiu o bloco triplo aberto (BTA). Na variável movimentações do bloco antes do passe de ataque, encontrámos as seguintes possibilidades adicionais: $\mathrm{BC}$ desloca-se para zona 4 (ANP); BP e BC marcam ataque ao $2^{\circ}$ toque (PC2); $\mathrm{BC}$ desloca-se para zona 2-3, antecipando ataque interior por zona 4 adversá- 
Quadro 1. Catálogo de ocorrências elaborado na observação inicial.

Disponibilidade da central para o ataque rápido

(DISPCEN)
Atacante central $(A C)$ no ataque rápido $(A R)$ à frente, junto da distribuidora

$A C$ no $A R$ à frente, afastada da distribuidora

$A C$ no AR atrás da distribuidora

$A C$ simula $A R$, mas atrasada

$A C$ simula $A R$, mas à frente da linha dos ombros da distribuidora

$A C$ não recupera de acção prévia

Primeiro toque de fraca qualidade, inviabilizando AR

$\mathrm{AC}$ recebe e prepara ataque por zona 2

\section{Bloco espera pelo passe de ataque}

Blocadora central (BC) desloca-se para zona 2

$\mathrm{BC}$ acompanha a $\mathrm{AC}$ em $\mathrm{AR}$ à frente, afastado da distribuidora

$\mathrm{BC}$ salta simultaneamente com $\mathrm{AC}$

Blocadora de zona 4 (BP) junta à $B C$

Blocadora de zona 2 (BS) junta à $B C$

$\mathrm{BC}$ e $\mathrm{BP}$ acompanham a $\mathrm{AC}$ na china 4

$\mathrm{BP}$ marca ataque ao $2^{\circ}$ toque

$\mathrm{BC}$ marca ataque ao $2^{\circ}$ toque

Bloco recua para defender

Sem bloco - blocadoras ficam na rede, sem tempo para recuar

Bloco individual, $\mathrm{BC}$ recua para defender

Bloco individual, $\mathrm{BC}$ não bloca nem defende

Bloco individual, subida atrasada

Bloco duplo coeso

Bloco duplo quebrado

Bloco duplo aberto

Bloco triplo

Erro da distribuidora, não havendo bloco

\begin{tabular}{l}
\hline SIC \\
SIT \\
SIA \\
ATR \\
FRE \\
NRC \\
1TK \\
ZO2 \\
\hline ESP \\
ANS \\
ANT \\
ANC \\
PCA \\
SCA \\
PCC \\
P2T \\
C2T \\
\hline OBO \\
OBL \\
BIO \\
BLI \\
BIA \\
BLD \\
BDQ \\
BDA \\
BLT \\
EDI \\
\hline
\end{tabular}

ria (CAP); BP acompanha a AC na china ( $\mathrm{PCH})$. Posteriormente, procedemos a uma análise associativa das variáveis em estudo.

\section{Procedimentos estatísticos e fiabilidade}

Para a análise exploratória recorremos à estatística descritiva, tendo-se obtido as frequências e respectivas percentagens para cada uma das categorias das variáveis em estudo (jogadas combinadas e tempos de ataque). Para percebermos a associação entre as variáveis estudadas, recorremos ao teste do QuiQuadrado, com a correcção de Monte Carlo, pois mais de $20 \%$ das células possuiam $n<5$. Para o estudo da fiabilidade foram analisadas
$23,13 \%$ das acções, valores substancialmente superiores aos de referência ( $10 \%)$, apontados pela literatura (43). A fiabilidade intra-observador e inter-observador mostrou valores de Kappa entre 0.99 e 1 para todas as variáveis, substancialmente superiores aos valores mínimos aceitáveis apontados pelas literatura (0.75) (18).

\section{RESULTADOS E DISCUSSÃO}

\section{Análise descritiva}

Disponibilidade da atacante central para o ataque rápido

Relativamente a esta variável, em $51.1 \%$ de situações (1TK, ATR, FRE, NRC) não se verificou uma real disponibilidade da central para atacar, o que limita, 
desde logo, as opções da distribuidora, tornando o ataque mais lento e previsível. Das vezes em que, efectivamente, a central se mostrou disponível para $\mathrm{o}$ ataque rápido, a situação mais comum foi a de tempo 1 junto da distribuidora (SIC) (18.4\%), seguido de tempo 1 atrás (SIA) (16.5\%) e tempo 1 afastado ou longe (SIT) (14.0\%).

Estes dados contrastam com a realidade observada no Voleibol masculino de alto nível, onde o tempo 1 afastado do distribuidor se configura como a ocorrência mais comum $(11,17)$. É nossa convicção que, num nível de rendimento competitivo mais elevado, no Voleibol feminino, o tempo 1 afastado e o tempo 1 atrás serão mais solicitados do que o tempo 1 junto, pelas vantagens que acarreta do ponto de vista do duelo distribuidora versus bloco, devendo ser objecto de análise em futuros estudos.

\begin{tabular}{c} 
Quadro 2. Frequências e percentagens das categorias \\
relativas à dimensão disponibilidade da central. \\
\hline \multicolumn{3}{c}{ Frequência } \\
\hline DISPCEN \\
\cline { 2 - 3 }
\end{tabular}

\section{Movimentações do bloco antes do passe de ataque}

Através do quadro 3, é possível constatar que, ao nível das movimentações das blocadoras antes do passe de ataque, a situação de espera (correspondente à estratégia de ler e reagir) foi a mais comum $(45,7 \%)$, o que reitera a necessidade de parcimónia na utilização de estratégias de compromisso (1, 10, 13, 30), particularmente no Voleibol feminino (41). Outra situação comum é a da blocadora central (BC) se deslocar (antecipadamente) para zona 2, prevendo um ataque de zona 4 pela equipa na posse de bola $(22,4 \%)$. Isto faz todo o sentido em virtude dos ataques de recurso serem os que mais facilmente permitem a antecipação por parte do bloco, tendendo, por isso, a ser direccionados para a atacante de ponta $(22,34)$. Todas as restantes situações têm ocorrências substancialmente reduzidas, levando-nos a equacionar que a sua ocorrência está dependente de constrangimentos situacionais singulares.

Quadro 3. Frequências e percentagens das categorias relativas à dimensão movimentações do bloco prévias ao passe de ataque

\begin{tabular}{cccc}
\hline & & Frequência & $\%$ \\
\hline MOVBLO & ANC & 19 & 4,7 \\
& ANP & 11 & 2,7 \\
ANS & 91 & 22,4 \\
ANT & 23 & 5,7 \\
C2T & 10 & 2,5 \\
CAP & 1 &, 2 \\
ESP & 186 & 45,7 \\
P2T & 15 & 3,7 \\
PC2 & 4 & 1,0 \\
PCA & 21 & 5,2 \\
PCC & 7 & 1,7 \\
PCH & 7 & 1,7 \\
SCA & 12 & 2,9 \\
Total & 407 & 100,0 \\
\hline
\end{tabular}

\section{Oposição do bloco}

No quadro 4, apresentam-se os resultados respeitantes à variável acção do bloco. O bloco duplo é a ocorrência mais comum (70.3\%), nas manifestações coeso (BLD - 47.2\%), quebrado (BDQ $12.3 \%$ ) e aberto (BDA - 10.8\%). Ao bloco duplo segue-se o bloco individual (19.4\%), nas suas vertentes regular (BLI - 12\%), por opção da equipa defensora (BIO - 5.4\%) e atrasado (BIA - 2\%). A inexistência de oposição por parte do bloco surge em terceiro, com $7.1 \%$ das ocorrências, sendo que $6,1 \%$ destas se referem à situação em que o bloco recua atempadamente para defender (0BO). Finalmente, o bloco triplo (coeso ou aberto), apenas ocorre em $2.2 \%$ das situações. No que concerne à supremacia do bloco duplo, seguido do bloco individual, os dados são concordantes com a bibliografia $(9,11,22,32,34,39)$. 
Quadro 4. Frequências e percentagens das categorias relativas à dimensão oposição do bloco.

\begin{tabular}{cccc}
\hline & & Frequência & $\%$ \\
\hline BLOCO & OBL & 4 & 1,0 \\
OBO & 25 & 6,1 \\
BDA & 44 & 10,8 \\
BDQ & 50 & 12,3 \\
BIA & 8 & 2,0 \\
BIO & 22 & 5,4 \\
BLD & 192 & 47,2 \\
BLI & 49 & 12,0 \\
BLT & 5 & 1,2 \\
BTA & 4 & 1,0 \\
EDI & 4 & 1,0 \\
Total & 407 & 100,0 \\
\hline
\end{tabular}

Relativamente à coesão do bloco, não se confirmam os resultados obtidos por Castro (11), em Voleibol masculino de alto nível. O autor verificou que $68.9 \%$ das situações de bloco duplo constituem bloco aberto, algo que não se confirmou com a nossa amostra, porquanto apenas $10.8 \%$ das situações constituíram bloco duplo aberto e $12.3 \%$ bloco quebrado. Tal pode dever-se à especificidade do Voleibol feminino, nomeadamente à menor velocidade do jogo quando o primeiro toque não possui boa qualidade.

\section{Análise associativa}

Disponibilidade da atacante central para o ataque rápido $e$ movimentações do bloco antes do passe de ataque

Através da análise inferencial, verificou-se uma relação de dependência entre a disponibilidade da central e as movimentações do bloco adversário, porquanto se regista um valor de Qui-Quadrado de 426.140, com um nível de significância de $p \leq 0,001$, para uma associação moderada ( $V$ de Cramer $=0,418)$. O quadro 5 apresenta os valores dos resíduos ajustados, que assumem significado sempre que o seu valor é superior a $|2|$.

É notório, nas situações em que as atacantes centrais não possuem disponibilidade efectiva para atacar bolas rápidas, a tendência do bloco esperar ou antecipar movimentações para a saída de rede, no sentido de interceptar eventuais ataques pela ponta, sendo aplicado a estratégia de ler e reagir. Já Selinger e Ackermann-Blount (41) comentavam que as estratégias de bloco de compromisso não eram tão necessárias no Voleibol feminino como no masculino, assumindo total pertinência esta assunção na actualidade.

Constata-se que, quando o primeiro toque é de fraca qualidade (1TK), as blocadoras centrais tendem a esperar (ESP - 46.4\%) ou a antecipar possíveis ataques de ponta (ANS - 44.9\%). É, também, evidente, que, quando a atacante central se atrasa, o bloco adopta um comportamento de espera (ESP), no sentido de não se precipitar, indo ao encontro do verificado por Afonso, Mesquita e Palao (1). De igual modo, quando a atacante central não recupera de uma acção prévia (recepção, bloco, etc.), a espera (ESP) continua a surgir como a categoria mais frequente $(54,2 \%)$, seguida de antecipação para a saída (ANS) $(31,3 \%)$. Isto revela, da parte das blocadoras, uma correcta leitura do jogo, o que se traduz numa calibração afinada entre a percepção da situação e a acção desencadeada $(4,15,20,21,23,29,37) 5$. Baseado neste entendimento, espera-se que, nas situações de ameaça real de ataque de primeiro tempo, a acção das blocadoras seja substancialmente distinta. Em função das regularidades verificadas, terá sentido propor que, em futuros estudos, as situações de indisponibilidade da atacante central para efectivar o ataque rápido (ATR, FRE, NRC e 1TK) sejam agrupadas numa só, denominada atacante central indisponível para o ataque rápido (IND).

A simulação de tempo 1 junto da distribuidora (SIC) hipoteca o bloco adversário, associando-se significativamente à ocorrência aumentada de estratégias de bloco de compromisso (ANC, PCA e CAP) e à diminuição de estratégias de ler e reagir (ESP), revelando forte calibração com as variáveis especificadoras configuradas pela situação. A simulação de tempo 1 afastado da distribuidora (SIT) configura-se como uma jogada de elevada eficácia sobre as movimentações do bloco anteriores à execução do passe de ataque. Neste sentido, interessaria que este tipo de jogada fosse utilizada mais vezes em relação ao tempo 1 junto da distribuidora (atrás ou à frente). Neste estudo, o tempo 1 afastado da distribuidora associou-se à ocorrência aumentada de estratégias de compromisso (ANT, P2T e SCA). Por seu turno, na simulação da central no tempo 1 atrás da distribuidora (SIA), verifica-se uma adaptação funcional do bloco a esta variável especificadora, associando-se à ocorrência 
Quadro 5. Associação entre as variáveis disponibilidade da central para o ataque rápido e movimentações do bloco antes do passe de ataque.

\begin{tabular}{|c|c|c|c|c|c|c|c|c|c|c|c|c|c|}
\hline DISPCEN & & & & & & & AOVBL & & & & & & \\
\hline & ANC & ANP & ANS & ANT & C2T & CAP & ESP & P2T & PC2 & PCA & PCC & $\mathrm{PCH}$ & SCA \\
\hline $1 \mathrm{TK}$ & $-3,2$ & 1,5 & 7,8 & $-3,5$ &,- 3 &,- 7 & ,2 & $-1,7$ &,- 4 & $-3,4$ & $-1,9$ & $-1,9$ & $-2,5$ \\
\hline ATR &,$- ?$ & -6 & $-1,8$ &,- 8 &,- 5 &,- 2 & 3,7 &,- 7 &,- 3 &,- 8 &,- 4 &,- 4 &,- 6 \\
\hline FRE & , ? &,- 6 &,- 3 &,- 8 &,- 5 &,- 2 & 1,8 &,- 7 &,- 3 &,- 8 &,- 4 &,- 4 &,- 6 \\
\hline NRC & $-1,6$ & $-1,2$ & 1,6 & $-1,8$ & 1,8 &,- 4 & 1,3 & 1,0 & ,8 & $-1,7$ & $-1,0$ & $-1,0$ & $-1,3$ \\
\hline SIA & $-2,0$ &,$- ?$ & $-3,5$ & $-1,6$ & 2,0 &,- 4 & 1,2 & , 4 &,- 9 & ,9 & 6,0 & 6,0 & $-1,6$ \\
\hline SIC & 8,8 &,- 8 & $-3,3$ & $-1,2$ & $-1,5$ & 2,1 & $-2,1$ &,- 5 & ,3 & 5,9 & $-1,3$ & $-1,3$ & 1,4 \\
\hline SIT & $-1,8$ & 1,3 & $-3,7$ & 10,4 & $-1,3$ &,- 4 & $-2,9$ & 2,2 & 6 &,- 6 & $-1,1$ & $-1,1$ & 5,3 \\
\hline
\end{tabular}

Quadro 6. Associação entre as variáveis disponibilidade da central para o ataque rápido e oposição do bloco.

\begin{tabular}{|c|c|c|c|c|c|c|c|c|c|c|}
\hline \multirow[t]{2}{*}{ DISPCEN } & \multicolumn{10}{|c|}{ OPOSIÇÃO DO BLOCO } \\
\hline & $\mathrm{OBL}$ & $\mathrm{OBO}$ & $\mathrm{BDA}$ & BDQ & $\mathrm{BIA}$ & $\mathrm{BIO}$ & BLD & $\mathrm{BLI}$ & BLT & BTA \\
\hline 1TK & $-1,4$ & 4,6 & $-2,3$ & $-3,5$ & $-2,0$ & 4,0 & 2,5 & $-3,4$ & 2,2 & $-1,4$ \\
\hline ATR &,- 3 &,- 9 &,- 2 & 2,5 &,- 5 &,- 8 &,- 1 & $-1,2$ &,- 4 & 2,8 \\
\hline FRE &,- 3 &,- 9 & $-1,2$ &,- 3 &,- 5 &,- 8 & 2,3 & $-1,2$ &,- 4 & 2,8 \\
\hline NRC & ,8 & $-1,2$ & $-1,6$ & ,0 & $-1,0$ & ,3 & 2,0 &,- 8 & 6 & ,8 \\
\hline SIA & 3,2 & $-1,7$ & 2,9 & 3,6 & ? & $-1,5$ & $-2,8$ & 0 & $-1,0$ &,- 9 \\
\hline SIC & $-1,0$ & $-1,4$ & 2,0 & 1,1 &, 5 & $-1,7$ & $-1,4$ & 1,6 & $-1,1$ & $-1,0$ \\
\hline SIT &,- 8 &,- 9 &,- 1 & $-1,3$ & 3,0 & $-1,3$ & $-1,7$ & 4,9 &,- 9 & ,6 \\
\hline
\end{tabular}

aumentada de marcação de ataques ao segundo toque (por parte da distribuidora) e da jogada de ataque denominada "china" (C2T, PCC e PCH).

Disponibilidade da atacante central para $o$ ataque rápido e oposição do bloco

$\mathrm{Na}$ associação entre as variáveis disponibilidade da central e acção do bloco, o valor de Qui-Quadrado foi de 171.261, com um nível de significância de $\mathrm{p} \leq 0,001$. O V de Cramer foi 0,265 ( $\mathrm{p} \leq 0,001$ ), apontando para uma associação moderada. O quadro 6 revela os resíduos ajustados para a associação entre estas variáveis.

A qualidade do primeiro toque é decisiva para uma construção rápida, variada e agressiva do ataque (7,24, $28,32,33,40)$, o que saiu reforçado pelos nossos dados, pois um primeiro toque de fraca qualidade (1TK) produziu $81,2 \%$ de situações favoráveis ao bloco (BLD, OBO e BIO). Daqui se infere que a análise da qualidade do primeiro toque é um indicador decisivo a percepcionar pela blocadora central.

Contrariamente ao estudo de Moutinho et al. (32), não se verificou um aumento significativo do número de blocos triplos, o que pode dever-se às diferenças entre Voleibol masculino e feminino.

As situações de ameaça real de ataque ao primeiro tempo influenciaram decisivamente as movimentações do bloco prévias ao passe de ataque, bem como a formação do bloco posterior ao passe de ataque, congruentemente com o postulado pela literatura (9, 10,16, 27). De facto, a simulação de tempo 1 atrás da distribuidora (SIA) promove $46,3 \%$ de situações de 
Quadro 7. Associação entre as variáveis movimentações do bloco antes do passe de ataque e oposição do bloco.

\begin{tabular}{|c|c|c|c|c|c|c|c|c|c|c|}
\hline \multirow[t]{2}{*}{ MOVBLO } & \multicolumn{10}{|c|}{ OPOSIÇÃO DO BLOCO } \\
\hline & $\mathrm{OBL}$ & $\mathrm{OBO}$ & BDA & $\mathrm{BDQ}$ & $\mathrm{BIA}$ & $\mathrm{BIO}$ & BLD & $\mathrm{BLI}$ & BLT & BTA \\
\hline ANC &,- 4 & $-1,1$ & 3,0 &, 5 &,- 6 & $-1,1$ & $-3,7$ & 3,4 &,- 5 &,- 4 \\
\hline ANP &,- 3 &,- 9 & ,8 &,- 3 & 1,7 &,- 8 &, 5 &,- 3 &,- 4 &,- 3 \\
\hline ANS & $-1,1$ &,- 3 & $-1,5$ & $-2,2$ & , 2 & 1,1 & 4,5 & $-3,3$ & $-1,2$ & $-1,1$ \\
\hline ANT &,- 5 & $-1,3$ & 3,1 & 1 &,- 7 & $-1,2$ & $-2,9$ & 4,1 &,- 6 &,- 5 \\
\hline С2Т & 2,9 &,- 8 & $-1,1$ & $-1,2$ &,- 5 &,- 8 & $-3,0$ & 7,7 &,- 4 &,- 3 \\
\hline CAP &,- 1 &,- 3 &,- 3 & -4 &,- 1 &,- 2 & 1,1 &,- 4 &,- 1 &,- 1 \\
\hline ESP & , 2 & 2,3 & $-1,3$ & 2,2 & $-1,2$ & 1,7 &,- 9 & $-2,9$ & 2,5 & 2,2 \\
\hline P2T & 2,3 & $-1,0$ &,- 5 & ,1 & 3,2 &,- 9 & $-2,7$ & 4,2 &,- 4 &,- 4 \\
\hline $\mathrm{PC2}$ &,- 2 &,- 5 &,- 7 & -8 &,- 3 &,- 5 & 2,1 &,- 7 &,- 2 &,- 2 \\
\hline PCA &,- 5 & , &,- 2 & -4 & ,9 & $-1,1$ & 1,8 & $-1,7$ &,- 5 &,- 5 \\
\hline $\mathrm{PCC}$ &,- 3 &,- 7 & 2,8 & 1,3 &,- 4 &,- 6 & $-1,0$ & $-1,0$ &,- 3 &,- 3 \\
\hline $\mathrm{PCH}$ &,- 3 & ,9 &,- 9 & ,2 &,- 4 &,- 6 &, 5 & ,2 &,- 3 &,- 3 \\
\hline SCA &,- 4 &,- 9 &,- 3 &,- 4 &,- 5 & , 5 & 2,0 & $-1,3$ &,- 4 &,- 4 \\
\hline
\end{tabular}

bloco duplo mal formado (quebrado ou aberto), depreendendo-se que é uma jogada que ameaça seriamente a compactidade do bloco adversário, fruto das movimentações que lhe exige.

Enquanto que a simulação de tempo rápido junto da distribuidora (SIC) se associou à ocorrência aumentada de bloco duplo aberto (BDA), a simulação de tempo rápido afastado da distribuidora (SIT) associou-se à ocorrência aumentada de bloco individual (BLI) e bloco individual atrasado (BIA). Neste sentido, a análise da movimentação da central adversária e da sua relação espaço-temporal com a distribuidora constitui-se como uma variável especificadora de enorme relevância, com a qual as blocadores deverão estar afinadas.

\section{Movimentações do bloco antes do passe}

de ataque e oposição do bloco

$\mathrm{Na}$ associação entre as variáveis movimentações do bloco e acção do bloco, o valor de Qui-Quadrado foi de 252,351, com um nível de significância de $\mathrm{p} \leq 0,001$. O V de Cramer foi 0,254 ( $\mathrm{p} \leq 0,001$ ), apontando para uma associação moderada. No quadro 7 , podemos observar os resíduos ajustados para a associação destas variáveis.

Como consequência de uma antecipação de ataques rápidos junto da distribuidora (ANC), aumentam as ocorrências de bloco duplo aberto e bloco individual. Importa saber, então, se, perante a ameaça de primeiro tempo junto da distribuidora, a atacante é eficaz; caso não o seja, a estratégia de compromisso no bloco poderá não aumentar de forma substancial a eficácia defensiva da equipa, para além de incrementar o risco da criação de situações de $1 \times 1$ nas extremidades da rede. $\mathrm{O}$ mesmo sucede com a utilização de estratégias de compromisso no bloco para antecipar ataques rápidos afastados da distribuidora (ANT).

A supremacia das estratégias do bloco de ler e reagir sobre as tácticas de antecipação ou compromisso $(9$, $10,16,27,41)$ é confirmada neste estudo. De facto, quando o bloco opta por uma estratégia de ler e reagir, isto é, quando espera (ESP), tende a produzir bloco duplo coeso (BLD - 44,6\%), associando-se à ocorrência aumentada de outras situações favoráveis ao bloco (OBO, BLT e BTA). 


\section{CONCLUSÕES}

O presente estudo demonstrou a importância da análise do jogo considerar variáveis especificadoras das acções dos jogadores, abrindo portas para outras vias de análise da tomada de decisão, para além do relato verbal que vulgarmente recorre a cenários de vídeo e/ou a entrevistas.

Conforme se verificou, a disponibilidade da central para o ataque rápido influi decisivamente nas acções do bloco adversário, antes e após o passe de ataque.

Os resultados renovam a necessidade de se ser rigoroso na utilização de estratégias antecipativas do bloco, sobretudo em situações nas quais a qualidade do primeiro toque ou as movimentações da atacante central denunciam, previamente, a impossibilidade de realizar ataque rápido pelo centro da rede. Na medida em que a tomada de decisão dinâmica, não raramente, se baseia mais na intuição do que na reflexão consciente, o treino deve criar situações ajustadas, propiciadoras do acoplamento percepção-acção.

Os resultados do nosso estudo sugerem ainda que, do ponto de vista da análise do jogo, a separação entre bloco duplo quebrado e aberto poderá nem sempre ser pertinente. Nomeadamente, se o objectivo for analisar o mérito da distribuidora, caso ocorra bloco duplo quebrado ou aberto, em ambos os casos, a acção da distribuidora provocou uma situação de desequilíbrio no bloco, materializada na chegada tardia da blocadora central. Contrariamente, poderá ser pertinente diferenciar estas categorias, bloco duplo aberto e quebrado, quando se analisa a acção de ataque, porquanto esta diferenciação deverá ser considerada pela atacante na direcção a imprimir ao remate e/ou na exploração do bloco. Por fim, os resultados sugerem a necessidade de, no Voleibol feminino, a simulação de ataque de tempo 1 afastado da distribuidora ser mais explorada, à semelhança do que sucede no Voleibol masculino, porquanto esta situação induziu situações vantajosas para a distribuidora, nas movimentações do bloco prévias ao passe de ataque. As conclusões provenientes do estudo relevam a importância do reconhecimento de regularidades do jogo que possibilitam a definição de probabilidades situacionais, preditoras de competências perceptivo-decisionais, contribuindo para a qualificação da tomada de decisão e para o incremento da eficácia das acções de jogo.

\section{NOTAS}

${ }^{1}$ Freeball - bola devolvida facilmente pelo oponente, com pouca velocidade horizontal (41)

${ }^{2}$ Downball - bola que, presumivelmente, será rematada mas sem necessidade de haver bloco, devido a uma condição deficiente do adversário para atacar (41).

${ }^{3}$ Nas condições de downball, a distribuidora deverá esperar até ao momento de definição do ataque, penetrando apenas após se assegurar de que não terá de defender.

${ }^{4}$ China - designação popular para uma jogada de ataque na qual o atacante realiza uma chamada paralelamente à rede $\mathrm{e}$ culminando num salto a um pé, tendo forte componente horizontal.

${ }^{5}$ Garganta (19) mencionava que o jogador percebe a informação como conjuntos de possibilidades, noção consideravelmente semelhante à de affordance.

\section{CORRESPONDÊNCIA}

\section{José Afonso}

Rua Marta Sampaio, 30, $2^{\circ}$ Andar, Habitação 3

4250-282 Porto, Portugal

E-mail: jafonsovolei@hotmail.com 


\section{REFERÊNCIAS BIBLIOGRÁFICAS}

1. Afonso J, Mesquita I, Palao JM (2005a). Relationship Between the Use of Commit-Block and the Number of Blockers and Block Effectiveness. International Journal of Performance Analysis in Sport, 5(2): 36-45.

2. Afonso J, Mesquita, I, Palao JM (2005b). Relationship between the tempo and zone of spike and the number of blockers against the hitters. International Journal of Volleyball Research, 8(1): 19-23.

3. Araújo D (2005). A Acção Táctica no Desporto: uma Perspectiva Geral. In O Contexto da Decisão. A Acção Táctica no Desporto. (Duarte Araújo, Ed.), 21-33. Lisboa: Visão e Contextos.

4. Araújo D (2006). Tomada de Decisão no Desporto. Lisboa: FMH Edições.

5. Bayer C (1994). O Ensino dos Desportos Colectivos. Lisboa: Dinalivro.

6. Beal D (2002). Sistemas y tacticas basicas de equipo. Curso Internacional de Entrenadores de Voleibol - Nível I: Manual del Entrenador. http://www.rfevb.com/formación (online, 27 de Julho de 2004).

7. Beal D, Crabb T (1996). Bloquear. In Guía de Voleibol de la A.E.A.V. (2 ${ }^{\text {a }}$ Ed.), 113-122. Barcelona (Espanha): Editorial Paidotrino.

8. Bellendier J (2002). Ataque de rotación en el voleibol, un enfoque actualizado. Efdeportes - Revista Digital, ano 8, 51. http://www.efdeportes.com/efd51 (online, 4 de Janeiro de 2003).

9. Bellendier J (2003). Una visión analítico-descriptiva del Mundial de Voleibol 'Argentina 2002'. Efdeportes - Revista Digital, ano 9, 60. http://www.efdeportes.com/efd60 (online, 26 de Julho de 2004).

10. Bizzocchi C (2000). O Voleibol de Alto Nível - da iniciação à competição. Fazendo Arte Editorial. São Paulo (Brasil).

11. Castro J (2006). Análise Zonal das Variáveis Caracterizadoras do Ataque, na Fase de Side Out, em Voleibol - Estudo Realizado em Selecções Nacionais de Elite. Tese de Monografia. Porto: FADEUP. Não publicado.

12. César B, Mesquita I (2006) Caracterização do ataque do jogador oposto em função do complexo de jogo, do tempo e do efeito do ataque: estudo aplicado no Voleibol feminino de elite. Revista Brasileira de Educação Física e Esporte, 20(1): 59-69.

13. Coleman J (1996). Defensa en la red: opción de bloqueo. In Guía de Voleibol de la A.E.A.V. (2 ${ }^{a}$ Edição), 263-279. Editorial Paidotribo. Barcelona (Espanha).

14. Cunha P, Marques A (2003). A Eficácia Ofensiva em Voleibol. Estudo da Relação entre a Qualidade do $1^{\circ}$ Toque e a Eficácia do Ataque em Voleibolistas Portuguesas da $1^{\text {a }}$ Divisão. In Investigação em Voleibol. Estudos ibéricos (Isabel Mesquita, Carlos Moutinho \& Rui Faria, Eds.), 180-189. Porto: FCDEF-UP.

15. Davids K, Kingsbury D, Bennett S, Handford C (2001). Information-Movement Coupling: Implications for the Organization of Research and Practice During Acquisition of Self-Paced Extrinsic Timing Skills. Journal of Sports Sciences, 19: 117-127.

16. Dias C (2004). A distribuição no voleibol: aplicar uma estratégia eficaz. Treino Desportivo, ano VI, $3^{\text {a }}$ série, 24: 51-59.

17. Esteves M (2006). Caracterização das Acções do Distribuidor e Zonas de Distribuição no Voleibol Masculino de Elite -
Comparação entre Dois Modelos de Observação. Tese de Monografia. Porto: FADEUP. Não publicado.

18. Fleiss JL (1981). Statistical Methods for Rates and Proportions ( $2^{\text {a }}$ Ed.). Wiley-Interscience.

19. Garganta J (1997). Modelação táctica do jogo de Futebol. Estudo da organização da fase ofensiva em equipas de alto rendimento. Dissertação de Doutoramento. Porto: FCDEF-UP. Não publicado.

20. Garganta J (2005). Dos constrangimentos da Acção à Liberdade de (Inter)acção, para um Futebol com Pés...e Cabeça. In O Contexto da Decisão. A Acção Táctica no Desporto. (Duarte Araújo, Ed.), 179-190. Lisboa: Visão e Contextos.

21. Gibson J (1979). The Ecological Approach to Visual Perception. Boston (EUA): Houghton Miffin.

22. Guerra I, Mesquita I (2003). As regularidades na aplicação do remate por zona 4 em voleibol em função das zonas alvo de ataque. Estudo aplicado no Campeonato do Mundo de cadetes femininos. In Investigação em Voleibol. Estudos Ibéricos. I.Mesquita, C.Moutinho \& R.Faria (Eds.), 169179. FCDEF-UP. Porto.

23. Handford C, Davids K, Bennett S, Button C (1997). Skill Acquisition in Sport: Some Applications of an Evolving Practice Ecology. Journal of Sports Sciences, 15: 621-640.

24. Hervás F (2003). Analítico o global? VoleyTotal, 1. http://www.rfevb.com (online, 27 de Julho de 2004).

25. Izquierdo C, Anguera Argilaga MT (2001). The Rol of the Morphokinetic Notational System in the Observation of Movement. ORAGE 2000. Aix-en-Provence (França).

26. Marcelino R (2007). Análise da performance táctica no Voleibol de elevado rendimento desportivo. Estudo em equipas participantes na Liga Mundial 2005. Dissertação de Mestrado. Porto: FADEUP.

27. Martinez N, Abreu P (2003). Influencias del rally point en la preparación de los voleibolistas. Efdeportes - Revista Digital, ano 9, 62. http://www.efdeportes.com/efd62 (online, 26 de Julho de 2004).

28. Mcreavy M (1996). Tácticas y Estrategia en Voleibol. In Guía de Voleibol de la A.E.A.V. (2ª Ed.), 169-179. Barcelona (Espanha): Editorial Paidotrino.

29. Mesquita I (2005). A Contextualização do Treino no Voleibol: a Contribuição do Construtivismo. In $\mathrm{O}$ Contexto da Decisão. A Acção Táctica no Desporto. (Duarte Araújo, Ed.), 355-378. Lisboa: Visão e Contextos.

30. Mesquita I, Guerra I, Araújo V (2002). Processo de Formação do Jovem Jogador de Voleibol. Centro de Estudos e Formação Desportiva. Lisboa.

31. Mosher M (1993). Blocking in the women's game. In Coaches Manual Level 4, 3/1-3/22. Volleyball Canada. Gloucester, Ontario (Canadá).

32. Moutinho C, Marques A, Maia J (2003). Estudo da estrutura interna das acções da distribuição em equipas de voleibol de alto nível de rendimento. In Investigação em Voleibol. Estudos Ibéricos. I.Mesquita, C.Moutinho \& R.Faria (Eds.), 107-129. FCDEF-UP. Porto.

33. Paolini M (2000). Volleyball - from young players to champions. Ancona (Itália): Humana Editrice.

34. Paulo A (2004). Efeito das condições do ataque na sua eficácia na fase de Side Out em voleibol. Estudo aplicado na selecção portuguesa sénior masculina no Campeonato do Mundo de 2002. Dissertação monográfica. FCDEF-UP. Porto. 
35. Paulo A (2007). Tomada de Decisão no Ataque em Voleibol. Estudo realizado com atacantes de zona 4 seniores femininos. Dissertação de Mestrado. Porto: FADEUP.

36. Paulo A, Mesquita I (2005). Caracterização do jogo ofensivo em função da zona de distribuição, da zona de ataque e da posição do bloco no side-out. Estudo aplicado no campeonato do mundo de voleibol de 2002. In Estudos 5, J.Pinto (Ed.), 121-133. Porto: FCDEF-UP.

37. Renshaw I, Davids K (2004). Nested Task Constraints Shape Continuous Perception-Action Coupling Control During Human Locomotor Pointing. Neuroscience Letters, 369, 93-98.

38. Ribeiro J (2004). Conhecendo o Voleibol. Rio de Janeiro (Brasil): Editora Sprint.

39. Santandreu C, Torrento N, Alcazar X (2004). Análisis comparativo de las acciones defensivas de primera línea en voleibol masculino. VoleyTotal, 12. http://www.rfevb.com (online, 27 de Julho de 2004).

40. Santos, P, Mesquita I. (2003). Análise das Sequências Ofensivas a Partir da Recepção do Serviço, em Função da Qualidade das Acções de Jogo: Estudo Aplicado no Voleibol no Escalão de Juvenis Masculinos. In Investigação em Voleibol. Estudos ibéricos (Isabel Mesquita, Carlos Moutinho \& Rui Faria, Eds.), 160-168. Porto: FCDEF-UP.

41. Selinger A, Ackermann-Blount J (1986). Arie Selinger's Power Volleyball. New York (E.U.A.): St.Martin's Press.

42. Suwara R (2005). Bloqueio. In A Bíblia do Treinador de Voleibol (Don Shondell \& Cecile Reynaud et col., Eds.), 241-257. Porto Alegre (Brasil): Artmed Editora.

43. Tabachnick B, Fidell L (1989). Using Multivariate Statistics. New York: Harper \& Row Publishers.

44. Williams AM, Ward P (2003). Perceptual Expertise: Development in Sport. In Expert Performance in Sports. Advances in Research on Sport Expertise (Janet L.Starkes \& K.Anders Ericsson, Eds.), 219-250. Champaign, Illionois (EUA): Human Kinetics. 